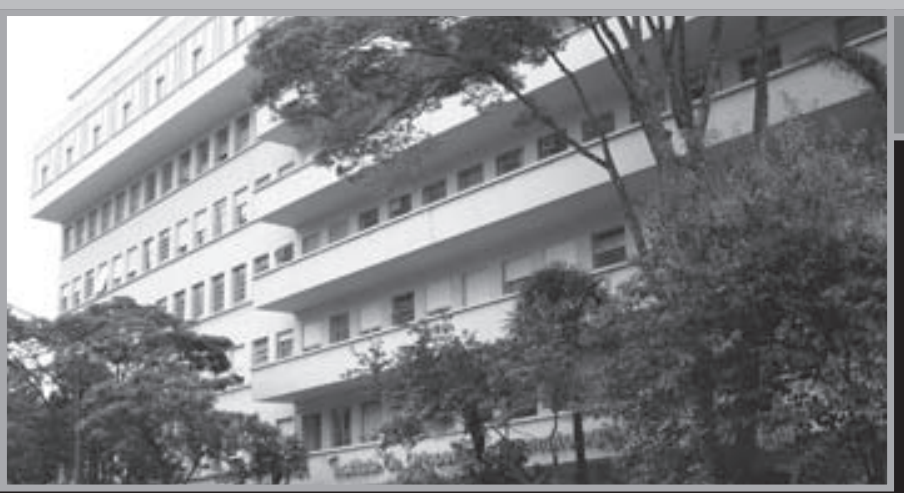

\section{A residência médica no Brasil}

Pouco mais de um século nos separa da criação do primeiro programa de residência médica atribuído a William Halsted, do Departamento de Cirurgia da Faculdade de Medicina da Universidade Johns Hopkins, em 1889. 0 cirurgião americano considerava precário o treinamento médico da época, realizado por tentativas e erros e com diferenças bastante expressivas nas oportunidades de formação. Outra observação do especialista era em relação à importância de uma programação de estudos e experiência prática logo após a graduação e sob supervisão criteriosa.
Fachada do Instituto de Ortopedia e Traumatologia do Hospital das Clinicas da Universidade de São Paulo.

No Brasil, os primeiros programas de residência médica datam da década de 1940 , sendo criados inicialmente nos dois principais centros de formação médica de então: São Paulo e Rio de Janeiro. 0 marco da criação de um programa de residência no país é conferido ao Hospital das Clínicas da Universidade de São Paulo (HC/USP), que exatamente em 1945 fez criar o primeiro programa de residência médica em ortopedia. Em 1948, o Instituto de Previdência e Assistência dos Servidores do Estado do Rio de Janeiro (IPASE-RJ) abriu as inscrições para seu primeiro curso de residência médica em psiquiatria, que também foi a especialidade premiada com um novo curso no HC/USP.

Os primeiros cursos de residência tinham turmas pequenas, cujos especialistas foram rapidamente absorvidos pelo mercado de trabalho. Só em 1977 foi criado o Conselho Nacional de Residência Médica e definidos os requisitos mínimos para algumas especialidades médicas. Outras apenas em 1983 tiveram seus critérios de admissão regulamentados. 